\title{
Medical morbidities and DNA methylation of NR3C1 in preterm infants
}

\author{
James Giarraputo ${ }^{1,2}$, Jordan DeLoach ${ }^{2,3}$, James Padbury ${ }^{4,5}$, Alper Uzun ${ }^{4,5}$, Carmen Marsit ${ }^{6}$, Katheleen Hawes ${ }^{2,4,5}$ and \\ Barry Lester $2,4,5,7$
}

BACKGROUND: Although there are no accepted "normal"levels of circulating cortisol in preterm infants, critically ill preterm infants show lower cortisol levels than healthy preterm infants. The regulation of cortisol reactivity by epigenetic changes in glucocorticoid receptor gene (NR3C1) expression has been demonstrated. This study aims to examine the relationship between medical morbidities in preterm infants and DNA methylation of NR3C1.

METHODS: Pyrosequencing was used to determine DNA methylation in $\mathrm{CpG}$ sites 1-4 of promoter region $1 \mathrm{~F}$ of $\mathrm{NR} 3 \mathrm{C}$. Cluster analysis placed 67 preterm infants born $<1,500 \mathrm{~g}$ into groups based on medical morbidities. The DNA methylation pattern was compared across groups.

RESULTS: Cluster analysis identified a high medical risk cluster and a low medical risk cluster. A Mann-Whitney U-test showed lower methylation at CpG1 for infants in the high-risk group $(M=0.336, S E=0.084)$ than infants in the low-risk group $(M=$ $0.617, \mathrm{SE}=0.109, P=0.032)$. The false discovery rate was low ( $q=$ 0.025). Cohen's D effect size was moderate (0.525).

CONCLUSION: Decreased DNA methylation of CpG1 of NR3C1 in high-risk infants may allow for increased binding of transcription factors involved in the stress response, repair and regulation of NR3C1. This may ensure healthy growth in highrisk preterm infants over increasing cortisol levels.

$\mathbf{P}$ reterm birth is frequently accompanied by significant medical problems, including bronchopulmonary dysplasia, retinopathy of prematurity, and infection (1-3). These complications are inversely proportional to gestational age at birth. Many of these morbidities are the result of hemodynamic instability, cardiovascular dysfunction and hypotension, and they are correlated with increased mortality and morbidity (4). The association of these problems with hypothalamic-pituitaryadrenal (HPA) function and dysregulation has been investigated intensively in preterm infants; these illnesses impact cortisol levels of preterm infants at discharge (5-7). Although there are no accepted "normal" levels of circulating cortisol in preterm infants, these infants have lower cortisol levels at discharge relative to full-term infants (8), and critically ill preterm infants show even lower cortisol levels than healthy preterm infants (4). Decreased cortisol levels can attenuate response to illnesses associated with prematurity by modulating the secretion of corticotropin-releasing hormone $(4,9)$.

Cortisol levels are regulated by the cross-talk of a sensitive feedback loop between the hormone products of the hypothalamus, pituitary, and adrenal gland. There are complex mechanisms for the regulation of hormone and hormone receptor expression and processing. A widely studied example is the regulation of cortisol responsiveness by epigenetic changes in glucocorticoid receptor gene (NR3C1) expression. In rodents, increased maternal care is associated with decreased DNA methylation, increased expression of hippocampal NR3C1, and decreased HPA responses to stress (lower levels of corticosterone) (10). In one study, human infants born to mothers with high prenatal stress demonstrated increased methylation of the NR3C1 promotor region, creating the potential for adult-onset disease (11). DNA methylation of the NR3C1 promoter in placenta has also been related to newborn neurobehavioral outcome (12). Maternal depression during pregnancy is also related to increased methylation of NR3C1 in this region $(12,13)$. However, decreased methylation of NR3C1 in this region is related to maternal smoking during pregnancy (14) and to worse newborn neurobehavior (15). In preterm infants, the postnatal environment has been shown to influence methylation of NR3C1, possibly affecting cortisol regulation (16). These results suggest that epigenetic mechanisms could play a role in the regulation of cortisol levels in preterm infants. To our knowledge, there are no studies of the association of epigenetic alterations in preterm infants with postnatal medical morbidities that could directly affect their neuroendocrine system function. The purpose of this exploratory study was to examine whether there are differences in DNA

\footnotetext{
'Department of Neuroscience, Brown University, Providence, Rhode Island; ${ }^{2}$ Warren Alpert Medical School of Brown University, Center for the Study of Children at Risk, Providence, Rhode Island; ${ }^{3}$ Department of Sociology, Brown University, Providence, Rhode Island; ${ }^{4}$ Warren Alpert Medical School of Brown University, Departments of Pediatrics, Providence, Rhode Island; ${ }^{5}$ Department of Pediatrics, Women and Infants Hospital of Rhode Island, Providence, Rhode Island; ${ }^{6}$ Department of Pharmacology and Toxicology and Epidemiology, Geisel School of Medicine at Dartmouth, Hanover, New Hampshire; ${ }^{7}$ Warren Alpert Medical School of Brown University, Departments of Psychiatry and Human Behavior, Providence, Rhode Island. Correspondence: Barry M. Lester (Barry_Lester@Brown.edu)

Received 7 March 2016; accepted 8 August 2016; advance online publication 2 November 2016. doi:10.1038/pr.2016.185
} 
methylation in the promoter region $1 \mathrm{~F}$ of $N R 3 C 1$ in preterm infants with varying levels of medical acuity before discharge from the Neonatal Intensive Care Unit (NICU).

\section{RESULTS}

Complete data were available for 63 infants. Infants in the high-risk medical cluster $(n=38)$ had more medical problems than infants in the low-risk medical cluster $(n=25)$ (Table 1$)$. There were statistically significant differences between the two clusters on 31 of the 36 medical variables. The 36 medical variables include Neonatal Therapeutic Intervention Scoring

Table 1. Model fit statistics for the cluster analysis

\begin{tabular}{lcccc}
\hline $\begin{array}{l}\text { Number } \\
\text { of clusters }\end{array}$ & $\begin{array}{c}\text { Schwarz's Bayesian } \\
\text { criterion (BIC) }\end{array}$ & $\begin{array}{c}\text { BIC } \\
\text { change }\end{array}$ & $\begin{array}{c}\text { Ratio of BIC Ratio of distance } \\
\text { changes }\end{array}$ & measures \\
\hline 1 & $3,703.34$ & & & \\
2 & $3,293.857$ & -409.482 & 1 & 2.44 \\
3 & $3,372.991$ & 79.134 & -0.193 & 2.296 \\
4 & $3,643.683$ & 270.692 & -0.661 & 1.129 \\
\hline
\end{tabular}

BIC, Bayesian Information Criterion.
System (NTISS) scores and several other clinical variables. Of note, eight out of the nine illness severity components of the NTISS score were significantly different between the two clusters. Likewise, among the major morbidities of prematurity, bronchopulmonary dysplasia and retinopathy of prematurity were significantly more common in the high-risk medical cluster than in the low-risk medical cluster while intraventricular hemorrhage and necrotizing enterocolitis were not. Thirteen out of the 15 treatments/interventions were used significantly more often in the high-risk medical cluster than in the low-risk medical cluster. A correlation matrix was generated to provide insight into the interrelationships of these variables (Figure 1). Attesting to the homogeneity of the patients enrolled, there were no statistically significant differences between the two clusters on demographic characteristics (Table 2). The population demographic results shown closely match the 2010 Rhode Island census (17), reflecting the population-based nature of our clinical services.

The average \% methylation at individual CpG sites 1-4 was analyzed and compared (Table 3, Figure 2). A Mann-Whitney $U$-test showed a lower mean percent methylation at CpG1 for infants in the high-risk cluster $(\mathrm{M}=0.336, \mathrm{SE}=0.084)$ than

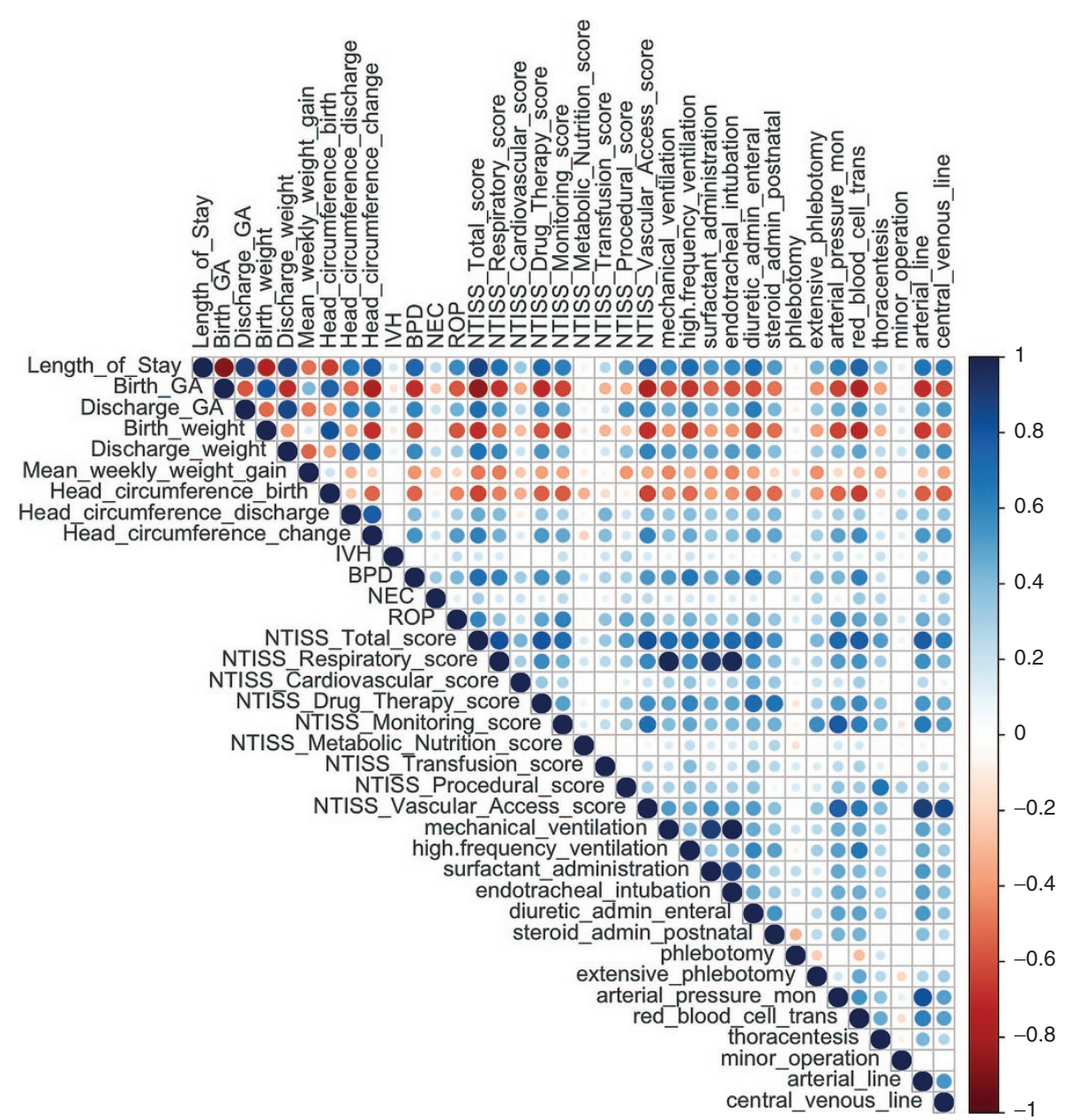

Figure 1. Correlation matrix of the clinical data and Neonatal Therapeutic Intervention Scoring System scores. In this correlation matrix, positive correlations are presented in blue and negative correlations are presented in red color. Color intensity and the size of the circle are proportional to the correlation coefficients. 
Table 2. Demographic characteristics of infants in the high medical risk and low medical risk groups

\begin{tabular}{|c|c|c|c|}
\hline & $\begin{array}{l}\text { High medical } \\
\text { risk }(n=38)\end{array}$ & $\begin{array}{l}\text { Low medical } \\
\text { risk }(n=25)\end{array}$ & $P$ \\
\hline Infant gender, female, $n(\%)$ & $21(55)$ & $15(60)$ & 0.710 \\
\hline Infant ethnicity & & & 0.129 \\
\hline Hispanic, $n(\%)$ & $10(28)$ & $3(12)$ & \\
\hline Non-Hispanic, $n$ (\%) & $26(72)$ & $22(88)$ & \\
\hline Infant race & & & 0.460 \\
\hline White, $n$ (\%) & $24(63)$ & $18(72)$ & \\
\hline African-American, $n$ (\%) & $3(78)$ & $2(8)$ & \\
\hline Asian, $n(\%)$ & $1(3)$ & $2(8)$ & \\
\hline Multi-racial, $n(\%)$ & $10(26)$ & $3(12)$ & \\
\hline Maternal ethnicity & & & 0.339 \\
\hline Hispanic, $n$ (\%) & $7(18)$ & $2(8)$ & \\
\hline Non-Hispanic, $n$ (\%) & $31(82)$ & $23(92)$ & \\
\hline Maternal race & & & 0.443 \\
\hline White, $n(\%)$ & $27(71)$ & $19(76)$ & \\
\hline African-American, $n(\%)$ & $4(11)$ & $2(8)$ & \\
\hline Asian, $n(\%)$ & $2(5)$ & $3(12)$ & \\
\hline Multi-racial, $n(\%)$ & $4(11)$ & $0(0)$ & \\
\hline Native American, $n(\%)$ & $1(3)$ & $1(4)$ & \\
\hline Maternal partner status & & & 0.674 \\
\hline Has a partner, $n(\%)$ & $32(84)$ & $22(88)$ & \\
\hline No partner, $n$ (\%) & $6(16)$ & $3(12)$ & \\
\hline Maternal education & & & 0.373 \\
\hline >High school, $n(\%)$ & $21(57)$ & $17(68)$ & \\
\hline$\leq$ High school, $n(\%)$ & $16(43)$ & $8(32)$ & \\
\hline Total & 38 & 25 & \\
\hline
\end{tabular}

infants in the low-risk cluster $(\mathrm{M}=0.617, \mathrm{SE}=0.109, P=0.032)$. The false discovery rate was low $(\mathrm{q}=0.025)$. The Cohen $\mathrm{D}$ effect size was moderate (0.525).

\section{DISCUSSION}

We found that preterm infants with more medical problems had a lower level of DNA methylation of the NR3C1 exon $1 \mathrm{~F}$ promoter region at $\mathrm{CpG} 1$ than infants with fewer medical problems. It is likely that these differences represent subpopulations of cells within our samples exhibiting differential methylation, and within those cells lead to functional changes in the expression of this gene. The proximal promoter of the NR3C1 gene has been widely studied in rodents (10) and its homolog region of the human infant $(11,13)$. This region contributes to regulation of the neuroendocrine system including the HPA axis and stress reactivity. CpG sites 1-4 were selected for this study based on animal and human studies of DNA methylation of NR3C1. This includes the original work of Weaver et al. (10) and later human studies by Oberlander et al. (13) and others. These sites are particularly important because they are binding sites for a number of important transcription factors that
Table 3. Mean percent methylation at NR3C1 CpG sites 1-4 for infants in the high medical risk and low medical risk groups

\begin{tabular}{lllc}
\hline CpG site & $\begin{array}{c}\text { High medical risk } \\
\text { group, M (SE) }\end{array}$ & $\begin{array}{c}\text { Low medical risk } \\
\text { group, M (SE) }\end{array}$ & $P$ \\
\hline 1 & $0.336(0.084)$ & $0.617(0.109)$ & 0.032 \\
2 & $0.262(0.064)$ & $0.327(0.113)$ & 0.839 \\
3 & $0.486(0.092)$ & $0.295(0.072)$ & 0.274 \\
4 & $0.454(0.095)$ & $0.366(0.110)$ & 0.535 \\
\hline CpG, 5'-cytosine-phosphate-guanine-3'. & &
\end{tabular}

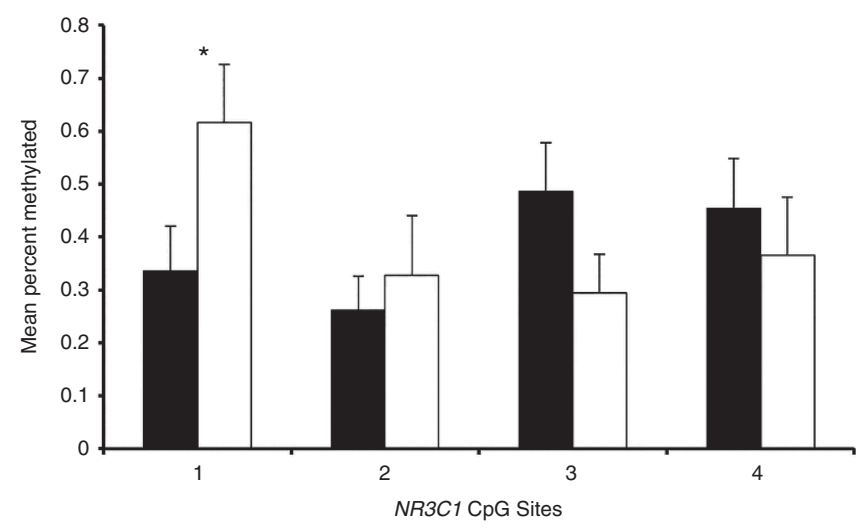

Figure 2. Mean percent methylation at $N R 3 C 1 C p G$ sites 1-4 for infants in the high medical risk and low medical risk groups. ${ }^{*} P=0.032$. Black $=$ High medical risk group. White $=$ Low medical risk group

regulate the expression of the NR3C1 gene such as NGF1-A (nerve growth factor) that is important for brain development (18). By contrast, in humans, little is known about the more distal sites making any differences between the high and low risk infants at these sites difficult, at best, to understand.

CpG1 is a binding site for the heat shock factor (HSF), p300, and ADR1 (alcohol dehydrogenase regulator) transcription factors (Figure 3). HSF upregulates genes in the heat shock pathway and other cellular stress responses, allowing for the mitigation of damage when a cell undergoes thermal stress and protects neurons from death caused by the misfolding of proteins (19). Heat shock factors lead to the activation of genes responsible for protecting the cell from various cellular and physiologic stressors, which may be particularly important in this population of preterm infants (20). Given the many medical morbidities in preterm infants, it is plausible that a more robust heat shock response would be accompanied by more HSF binding to NR3C1 at CpG1. Thus decreased methylation of CpGlin the high medical risk group may mediate a more active heat shock response, increasing transcriptional activation of the NR3C1 gene. p300 is important for the regulation of cell growth and division, as well as maturation and differentiation (21). This transcription factor has been shown to play an important role in tumor suppression and cell proliferation or apoptosis (22). ADR1 is involved in the regulation of glucose metabolism (23). Our results may suggest that p300 and ADR1 may also be more active in the higher medical risk group. This may be important in this population at risk for illnesses 


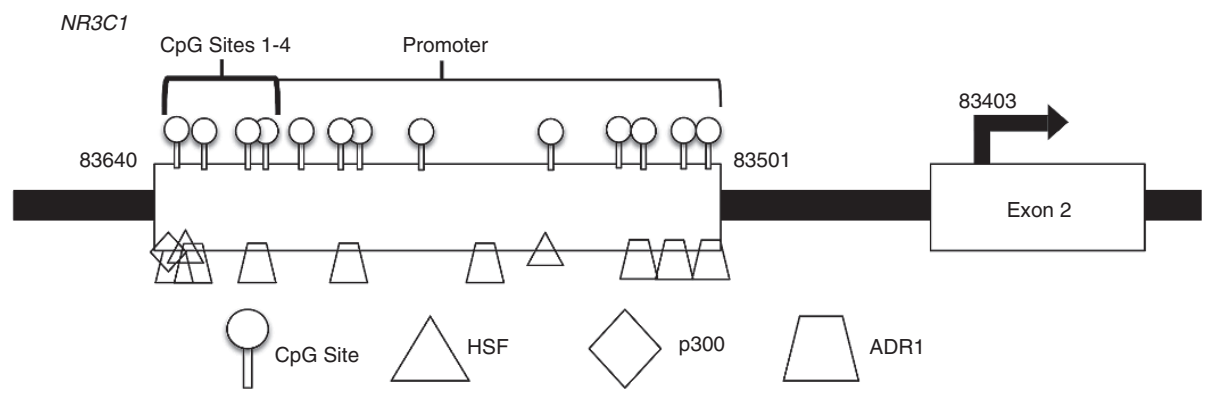

Figure 3. Schematic of the NR3C1 promoter and transcription factors of interest.

associated with deviations from the normal developmental trajectory. Thus, we speculate that CpG1 may be involved in the response to illness and mediating protective adaptations, including altered glucocorticoid receptor expression.

We also speculate that the difference in DNA methylation that we found between infants with more vs. fewer medical problems promotes adaptive programming. In the sicker infants, lower methylation of the NR3C1 promotor would lead to greater expression of glucocorticoid receptor, giving rise to a greater feedback suppression of adrenocorticotropic hormone (ACTH) release when the glucocorticoid receptor is occupied by circulating cortisol levels. Many of the morbidities in infants with high medical risk impact the neuroendocrine system and the number of medical morbidities is likely to lead to cumulative stress to the neuroendocrine system. The combination of these two factors over the course of a lengthy stay in high medical risk infants could result in a less responsive or underactive HPA axis. This can be a form of chronic stress for these infants and there is substantial literature showing that chronic stress results in an underactive HPA system with long-term deleterious consequences $(24,25)$. In addition, decreased NR3C1 promoter DNA methylation in the infants with more medical problems may allow for increased binding of the HSF, p300, and ADR1 transcription factors that are involved in stress response and repair ensuring and regulating healthy growth, which could be a physiological priority over increasing cortisol levels. Our results show that methylation of CpG1 is greater in low risk infants compared to high risk infants with more medical problems. As healthier preterm infants recover and approach discharge from the NICU, altered programming of the neuroendocrine system could result in an increase in cortisol to more normal levels $(2-4)$. We predict that over time, as the high medical risk infants recover, we would see a shift in methylation patterns toward increased methylation as seen in the low medical risk group.

This study has strengths and limitations. It is novel data among a group of extremely ill, but well-phenotyped, patients. The analytical approach has been previously validated by ourselves and others. Nonetheless, we did not measure cortisol levels. Therefore, we lack direct evidence that cortisol levels differed between the two groups. Second, exogenous dexamethasone was given to $29 \%$ of the infants in the group with more medical problems and was not used at all in the group with fewer medical problems. This is not surprising since $68 \%$ of the infants with more medical problems had bronchopulmonary dysplasia. Third, the percent methylation values of all sites were low, below $1 \%$, similar to those levels we and others have seen in prior human studies using accessible samples $(13,26,27)$. That said, we are pointing to the differences between the methylation levels in the two medical risk groups rather than the levels themselves. In fact, low levels of methylation of NR3C1 are the norm for the $\mathrm{CpG}$ sites more proximal to the promoter. The magnitude of methylation is not related to the presumed importance of specific regions of the gene. Little is known about the meaning of methylation levels at the more distal sites in humans, even though these are the sites with higher methylation levels. Finally, this study was, in part, exploratory. We did not hypothesize the direction of effects. We did, however, hypothesize differences in the CpG 1-4 region.

Important new studies are needed to clarify the implications of our results beyond just the measurement of neonatal cortisol levels. What are the levels of ACTH, Dehydroepiandrosterone (DHEA), and other important hormones? Most importantly, what is the level of HPA reactivity? Adrenal stimulation tests, with and without basal ACTH levels, have been widely used to identify adrenal insufficiency in the NICU (5). Such testing of HPA function including a combination of assessment of basal and stimulated cortisol production and comparison with NR3C1 promoter methylation would clarify the role of these mechanisms in early programming and perhaps risk of life-long disease (28).

\section{Conclusion}

This study of preterm infants shows that medical factors are related to DNA methylation of the NR3C1 promoter. This alteration may regulate cortisol levels. If so, this mechanism may be responsible for the observed differences in cortisol levels related to medical problems in preterm infants. These results contribute to our understanding of the consequences of prematurity. DNA methylation of NR3C1 has been studied in many populations and has been shown to be related to newborn neurobehavior (29), cortisol reactivity in infants (13), environmental adversity (parenting) (30,31), childhood psychopathology, maltreatment, and suicide (32). It is well documented that preterm infants are at increased risk for later neurodevelopmental and cognitive impairment $(33,34)$ and behavior disorders $(35-37)$. Thus, our findings could have implications for the long-term development of preterm infants and provide additional understanding of epigenetic activity related to neonatal medical risk that may have longer-term consequences. 


\section{Articles | Giarraputoet al.}

Table 4. Medical characteristics of infants in the high medical risk and low medical risk groups

\begin{tabular}{|c|c|c|c|}
\hline & High medical risk ( $n=38$ ) & Low medical risk $(n=25)$ & $P$ \\
\hline Birth weight, g (SD) & $920.66(265.0)$ & $1,241.6(188.7)$ & 0.000 \\
\hline Discharge weight, g (SD) & $3,413.68(526.6)$ & $2,359(525.4)$ & 0.000 \\
\hline Discharge GA, weeks (SD) & $40.83(2.54)$ & $37.27(1.75)$ & 0.000 \\
\hline Mean weekly weight gain, g/kg/day (SD) & $16.24(1.63)$ & $18.66(3.42)$ & 0.000 \\
\hline Head circumference (discharge), cm (SD) & $35.24(2.48)$ & $32.44(1.91)$ & 0.000 \\
\hline Head circumference (change), cm (SD) & $10.97(3.81)$ & $5.04(2.33)$ & 0.000 \\
\hline NTISS total score, (SD) & $31.76(5.65)$ & $18.6(3.39)$ & 0.000 \\
\hline NTISS respiratory score, (SD) & $6.4(0.5)$ & $2.36(1.68)$ & 0.000 \\
\hline NTISS metabolic score, (SD) & $4.05(0.32)$ & $3.96(0.2)$ & 0.207 \\
\hline NTISS transfusion score, (SD) & $1.71(1.37)$ & $0.24(0.66)$ & 0.000 \\
\hline NTISS procedural score, (SD) & $2.18(1.81)$ & $0.76(1.05)$ & 0.001 \\
\hline NTISS vascular access score, (SD) & $4.37(1.05)$ & $2(1.30)$ & 0.000 \\
\hline Intraventricular hemorrhage, $n(\%)$ & $11(29)$ & $5(20)$ & 0.433 \\
\hline Bronchopulmonary dysplasia, $n(\%)$ & $26(68)$ & $2(8)$ & 0.000 \\
\hline Necrotizing enterocolitis, $n(\%)$ & $10(26)$ & $3(12)$ & 0.175 \\
\hline Retinopathy of prematurity, $n(\%)$ & $18(47)$ & $2(8)$ & 0.001 \\
\hline Steroid administration, $n(\%)$ & $11(29)$ & $0(0)$ & 0.003 \\
\hline Phlebotomy (5-10), $n$ (\%) & $28(74)$ & $17(68)$ & 0.632 \\
\hline Extensive phlebotomy $(>10), n(\%)$ & $33(87)$ & $15(60)$ & 0.014 \\
\hline Arterial pressure monitoring, $n(\%)$ & $26(68)$ & $2(8)$ & 0.000 \\
\hline Red blood cell transfusion $(<15), n(\%)$ & $27(71)$ & $3(12)$ & 0.000 \\
\hline Thoracentesis, $n$ (\%) & $11(29)$ & $1(4)$ & 0.013 \\
\hline Minor operation, $n(\%)$ & $14(37)$ & $7(28)$ & 0.474 \\
\hline Arterial line, $n(\%)$ & $28(74)$ & $2(8)$ & 0.000 \\
\hline Central venous line, $n(\%)$ & $36(95)$ & $11(44)$ & 0.000 \\
\hline
\end{tabular}

GA, gestational age; NTISS, Neonatal Therapeutic Intervention Scoring System.

\section{METHODS}

The sample included 63 infants born $<1,500 \mathrm{~g}$ enrolled within $2 \mathrm{wk}$ of hospital discharge from the NICU at Women \& Infants Hospital of Rhode Island. Exclusion criteria included; non-English speaking or $<18$-y-old mother, infant congenital anomalies, or transfer. The hospital institutional review board approved the study, and written informed consent was obtained from all participants.

\section{Medical Outcomes}

Medical outcomes and demographic data were prospectively defined using definitions from the NICHD Neonatal Research Network.
Data were abstracted from the hospital electronic database. These included birth weight, discharge weight, birth GA, discharge gestational age (GA), mean weekly weight gain, length of stay, head circumference at birth, head circumference at discharge, total change in head circumference, intraventricular hemorrhage, bronchopulmonary dysplasia, necrotizing enterocolitis, and retinopathy of prematurity. Additionally, the use of any of the following treatments were recorded: mechanical ventilation, high-frequency ventilation, surfactant administration, endotracheal intubation, diuretic administration, phlebotomy, arterial pressure monitoring, red blood cell transfusion, thoracentesis, minor operation, arterial line, and use of 
a central venous line. The NTISS is a measure of therapeutic intensity and provides an index of neonatal illness severity and resource utilization throughout length of stay in the NICU. The NTISS scores were used to assess illness severity and medical interventions (38). After normalizing each row for NTISS scores and the clinical data in the matrix, we illustrated the inter-relationships between the clinical data, the illness severity scores, and the NTISS scores. Figure 2 demonstrates the correlation of the clinical data and NTISS scores with each other. In order to visualize this correlation, we used the corrplot package in the $\mathrm{R}$ program.

\section{DNA Methylation Analysis}

Genomic DNA was extracted from buccal epithelial cells collected just prior to discharge from the NICU using Oragene Discover for assisted collection using the prepIT kit (DNA Genotek, (Kanata, Ontario, Canada), and subjected to bisulfite modification using the EZ DNA methylation Kit (Zymo Research, Irvine, CA). Pyrosequencing was performed on PCR product amplified from bisulfite modified DNA as described previously (39). The primers for amplification were Forward: 5'-TTTTTTTTTT GAAGTTTTTT TA-3' and Reverse: $5^{\prime}$-Biotin-CCCCCAACTC CCCAAAAA-3'. The sequencing primer was designed to sequence the first five CpG sites ( $5^{\prime}$-GAGTGGGTTT GGAGT-3'). Percent DNA methylation at each CpG site was quantified using the Pyro Q-CpG software, version 1.0.11 (Qiagen, Valencia, CA). Bisulfite conversion controls were included with each sequencing run. In order for the sample's DNA methylation extent to be called, the bisulfite conversion rate must be $>93 \%$, and for all samples examined the conversion rate was $>95 \%$. All samples were sequenced in triplicates from the same bisulfite converted DNA template, and if the repeats differed by $>10 \%$ the sample was repeated.

\section{Statistical Methods}

One-way ANOVA was used for continuous medical and demographic variables, $\chi 2$ for dichotomous variables. A Mann-Whitney $U$-test was used for methylation variables, which were not normally distributed. Cluster analysis (SPSS Cluster Analysis) was used to group the infants into mutually exclusive groups based on medical problems. Given the estimated models, the model with the lower value of Bayesian Information Criterion is the one to be preferred. Both continuous and categorical variables can be used with this type of algorithm. The cluster analysis resulted in two categories based on Bayesian Information Criterion (Table 4). The Benjamini and Hochberg method (false discovery rate, $\mathrm{q}<0.10$ ) was used to determine the percent of findings that could be a false discovery (40). Since this was, in part, an exploratory study, we used a $\mathrm{q}$ of 0.10 , which is conservative but not stringent.

\section{ACKNOWLEDGMENTS}

We would like to thank Lynne Dansereau and Matthew Hinkley for helpful discussion, and Lee Breault for outstanding administrative support.

\section{STATEMENT OF FINANCIAL SUPPORT}

No financial assistance was received to support this study.

Disclosure: The authors have no financial relationships relevant to this article to disclose.

\section{REFERENCES}

1. Watterberg KL, Gerdes JS, Cook KL. Impaired glucocorticoid synthesis in premature infants developing chronic lung disease. Pediatr Res 2001;50:190-5.

2. Ng PC, Kwok AK, Lee CH, et al. Early pituitary-adrenal responses and retinopathy of prematurity in very low birth weight infants. Pediatr Res 2004;55:114-9.

3. Witt CL. Adrenal insufficiency in the term and preterm neonate. Neonatal Netw 1999;18:21-8.

4. Fernandez EF, Montman R, Watterberg KL. ACTH and cortisol response to critical illness in term and late preterm newborns. J Perinatol 2008;28: 797-802.

5. Fernandez EF, Watterberg KL. Relative adrenal insufficiency in the preterm and term infant. J Perinatol 2009;29 Suppl 2:S44-9.

6. Langer M, Modi BP, Agus M. Adrenal insufficiency in the critically ill neonate and child. Curr Opin Pediatr 2006;18:448-53.
7. Tantivit P, Subramanian N, Garg M, Ramanathan R, deLemos RA. Low serum cortisol in term newborns with refractory hypotension. J Perinatol 1999;19:352-7.

8. Ng PC. Is there a "normal" range of serum cortisol concentration for preterm infants? Pediatrics 2008;122:873-5.

9. Hanna CE, Keith LD, Colasurdo MA, et al. Hypothalamic pituitary adrenal function in the extremely low birth weight infant. J Clin Endocrinol Metab 1993;76:384-7.

10. Weaver IC, Cervoni N, Champagne FA, et al. Epigenetic programming by maternal behavior. Nat Neurosci 2004;7:847-54.

11. Mulligan CJ, D'Errico NC, Stees J, Hughes DA. Methylation changes at $\mathrm{NR} 3 \mathrm{C} 1$ in newborns associate with maternal prenatal stress exposure and newborn birth weight. Epigenetics 2012;7:853-7.

12. Conradt E, Lester BM, Appleton AA, Armstrong DA, Marsit CJ. The roles of DNA methylation of NR3C1 and $11 \beta-\mathrm{HSD} 2$ and exposure to maternal mood disorder in utero on newborn neurobehavior. Epigenetics 2013;8:1321-9.

13. Oberlander TF, Weinberg J, Papsdorf M, Grunau R, Misri S, Devlin AM. Prenatal exposure to maternal depression, neonatal methylation of human glucocorticoid receptor gene (NR3C1) and infant cortisol stress responses. Epigenetics 2008;3:97-106.

14. Stroud LR, Papandonatos GD, Rodriguez D, et al. Maternal smoking during pregnancy and infant stress response: test of a prenatal programming hypothesis. Psychoneuroendocrinology 2014;48:29-40.

15. Stroud LR, Papandonatos GD, Salisbury AL, et al. Epigenetic regulation of placental NR3C1: mechanism underlying prenatal programming of infant neurobehavior by maternal smoking? Child Dev 2016;87:49-60.

16. Kantake M, Yoshitake H, Ishikawa H, Araki Y, Shimizu T. Postnatal epigenetic modification of glucocorticoid receptor gene in preterm infants: a prospective cohort study. BMJ Open 2014;4:e005318.

17. United States Census Bureau. Rhode Island, 2014. (https://www.census. gov/quickfacts/table/PST045215/44).

18. Aloe L, Rocco ML, Bianchi P, Manni L. Nerve growth factor: from the early discoveries to the potential clinical use. J Transl Med 2012;10:239.

19. Verma P, Pfister JA, Mallick S, D'Mello SR. HSF1 protects neurons through a novel trimerization- and HSP-independent mechanism. J Neurosci 2014;34:1599-612.

20. Abane R, Mezger V. Roles of heat shock factors in gametogenesis and development. FEBS J 2010;277:4150-72.

21. Goodman RH, Smolik S. CBP/p300 in cell growth, transformation, and development. Genes Dev 2000;14:1553-77.

22. Wang F, Marshall CB, Ikura M. Transcriptional/epigenetic regulator CBP/ p300 in tumorigenesis: structural and functional versatility in target recognition. Cell Mol Life Sci 2013;70:3989-4008.

23. Young ET, Saario J, Kacherovsky N, Chao A, Sloan JS, Dombek KM. Characterization of a p53-related activation domain in Adrlp that is sufficient for ADR1-dependent gene expression. J Biol Chem 1998;273: 32080-7.

24. McEwen BS. Stress, adaptation, and disease. Allostasis and allostatic load. Ann N Y Acad Sci 1998;840:33-44.

25. Shonkoff JP, Boyce WT, McEwen BS. Neuroscience, molecular biology, and the childhood roots of health disparities: building a new framework for health promotion and disease prevention. JAMA 2009;301:2252-9.

26. Armstrong DA, Lesseur C, Conradt E, Lester BM, Marsit CJ. Global and gene-specific DNA methylation across multiple tissues in early infancy: implications for children's health research. FASEB J 2011;6:566-572.

27. Tyrka AR, Ridout KK, Parade SH, Paquette A, Marsit CJ, Seifer R. Childhood maltreatment and methylation of FK506 binding protein 5 gene (FKBP5). Dev Psychopathol 2015;27(4 Pt 2):1637-45.

28. Gluckman PD, Cutfield W, Hofman P, Hanson MA. The fetal, neonatal, and infant environments-the long-term consequences for disease risk. Early Hum Dev 2005;81:51-9.

29. Bromer C, Marsit CJ, Armstrong DA, Padbury JF, Lester B. Genetic and epigenetic variation of the glucocorticoid receptor (NR3C1) in placenta and infant neurobehavior. Dev Psychobiol 2013;55:673-83.

30. Melas PA, Wei Y, Wong CC, et al. Genetic and epigenetic associations of MAOA and NR3C1 with depression and childhood adversities. Int J Neuropsychopharmacol 2013;16:1513-28. 


\section{Articles | Giarraputo et al.}

31. Tyrka AR, Price LH, Marsit C, Walters OC, Carpenter LL. Childhood adversity and epigenetic modulation of the leukocyte glucocorticoid receptor: preliminary findings in healthy adults. PLoS One 2012;7:e30148.

32. McGowan PO, Sasaki A, D'Alessio AC, et al. Epigenetic regulation of the glucocorticoid receptor in human brain associates with childhood abuse. Nat Neurosci 2009;12:342-8.

33. Stephens BE, Vohr BR. Neurodevelopmental outcome of the premature infant. Pediatr Clin North Am 2009;56:631-46, Table of Contents.

34. Milligan DW. Outcomes of children born very preterm in Europe. Arch Dis Child Fetal Neonatal Ed 2010;95:F234-40.

35. Reef J, van Meurs I, Verhulst FC, van der Ende J. Children's problems predict adults' DSM-IV disorders across 24 years. J Am Acad Child Adolesc Psychiatry 2010;49:1117-24.

36. Hack M, Youngstrom EA, Cartar L, et al. Behavioral outcomes and evidence of psychopathology among very low birth weight infants at age 20 years. Pediatrics 2004;114:932-40.

37. Hille ET, Dorrepaal C, Perenboom R, Gravenhorst JB, Brand R, VerlooveVanhorick SP; Dutch POPS-19 Collaborative Study Group. Social lifestyle, risk-taking behavior, and psychopathology in young adults born very preterm or with a very low birthweight. J Pediatr 2008;152:793-800, 800.e1-4.

38. Gray JE, Richardson DK, McCormick MC, Workman-Daniels K, Goldmann DA. Neonatal therapeutic intervention scoring system: a therapybased severity-of-illness index. Pediatrics 1992;90:561-7.
39. Filiberto AC, Maccani MA, Koestler D, et al. Birthweight is associated with DNA promoter methylation of the glucocorticoid receptor in human placenta. Epigenetics 2011;6:566-72.

40. Benjamini Y, Hochberg Y. Controlling the false discovery rate: a practical and powerful approach to multiple testing. J R Stat Soc B (Methodological) 57, 289-300 (1995).

(1) (2) This work is licensed under a Creative Commons Attribution-NonCommercial-ShareAlike 4.0 International License. The images or other third party material in this article are included in the article's Creative Commons license, unless indicated otherwise in the credit line; if the material is not included under the Creative Commons license, users will need to obtain permission from the license holder to reproduce the material. To view a copy of this license, visit http://creativecommons.org/ licenses/by-nc-sa/4.0/

(c) The Author(s) (2016) 